\title{
Glycaemic Control Impact on Renal Endpoints in Diabetic Patients on Haemodialysis
}

\author{
Danielle Creme and Kieran McCafferty \\ Royal London Hospital, Whitechapel Road, London E1 1BB, UK \\ Correspondence should be addressed to Danielle Creme; dcreme@gmail.com
}

Received 6 July 2015; Revised 4 September 2015; Accepted 6 September 2015

Academic Editor: Alessandro Amore

Copyright ( 2015 D. Creme and K. McCafferty. This is an open access article distributed under the Creative Commons Attribution License, which permits unrestricted use, distribution, and reproduction in any medium, provided the original work is properly cited.

Objective. To identify the number of haemodialysis patients with diabetes in a large NHS Trust, their current glycaemic control, and the impact on other renal specific outcomes. Design. Retrospective, observational, cross-sectional study. Methods. Data was collected from an electronic patient management system. Glycaemic control was assessed from $\mathrm{HbAlc}$ results that were then further adjusted for albumin $(\mathrm{Alb})$ and haemoglobin $(\mathrm{Hb})$. Interdialytic weight gains were analysed from weights recorded before and after dialysis, 2 weeks before and after the most recent HbAlc date. Amputations were identified from electronic records. Results. 39\% of patients had poor glycaemic control (HbAlc $>8 \%)$. Adjusted HbAlc resulted in a greater number of patients with poor control (55\%). Significant correlations were found with interdialytic weight gains $(P<0.02, r=0.14)$, predialysis sodium $(P<0.0001, r=-1.9)$, and predialysis bicarbonate $(P<0.02, r=0.12)$. Trends were observed with albumin and C-reactive protein. Patients with diabetes had more amputations (24 versus 2). Conclusion. Large number of diabetic patients on haemdialysis have poor glycaemic control. This may lead to higher interdialytic weight gains, larger sodium and bicarbonate shifts, increased number of amputations, and possibly increased inflammation and decreased nutritional status. Comprehensive guidelines and more accurate long-term tests for glycaemic control are needed.

\section{Introduction}

Diabetes and renal disease are both long-term conditions prevalent in the adult UK population at $14 \%$ and $7.5 \%$, respectively [1]. The single most common aetiology of CKD is diabetic nephropathy. It is estimated that a quarter of all people with diabetes will develop end stage renal failure (ESRF), causing $21 \%$ and $11 \%$ of all deaths in type 1 and type 2 diabetes, respectively [2].

For people with diabetes requiring dialysis, one-year mortality rate was $17 \%$ compared with $11 \%$ for nondiabetic dialysis patients [3]. Other factors influence mortality such as old age, male gender, South Asian ethnicity, and lower socioeconomic status [4].

Slowing progression to ESRF in this patient group is the main treatment strategy for patients with diabetic nephropathy. While there is a plethora of research and evidence on methods and treatment to achieve this, outcomes and care once RRT (renal replacement therapy) has been initiated are less well defined.
It has been suggested that this patient group has a higher risk of complications such as cardiovascular disease, vascular calcification, infection, lower limb amputation, peripheral neuropathy, retinopathy, difficulties with vascular access, depression, and generalized decrease in quality of life (QoL) [5]. The severity of these complications could be mediated with better glycaemic control even after RRT initiation.

Aims. Aims of the study were to assess the prevalence of diabetes in the haemodialysis population to categorise the glycaemic control of the HD population into high and low risk categories and investigate the impact of poor glycaemic control on other renal specific outcomes.

\section{Methods}

Ethical approval was provided by the Clinical Effectiveness Unit and Audit Unit at Barts Health NHS Trust (registration number 5413). All patients on haemodialysis (HD) in August 
2014 were included. Data was extracted from electronic data records (Renalware).

Inclusion criteria were patients $>18$ years, currently on HD at Barts Health NHS Trust. Patients without diabetes or an $\mathrm{HbAlc}$ were excluded from the biochemical analysis.

The most recent recorded HbAlc was used to quantify glycaemic control. The patients were then stratified into $\mathrm{HbAlc}$ ranges to assess glycaemic control. Stratification was based on available published evidence. All other biochemistry and amputation data was extracted from Renalware at the time of the individuals HbAlc date.

Interdialytic weight gains (IDWG) were calculated using weights before and after dialysis, 2 weeks before and after HbAlc date. Nonparametric data was analyzed using the Kruskal-Wallis test statistic with Dunn's postcomparison test while correlations were quantified using the Spearman correlation coefficients with GraphPad Prism 6 software (San Diego, CA, USA).

$\mathrm{HbAlc}$ was further adjusted for $\mathrm{HD}$ accounting for changes in albumin (Alb) and haemoglobin ( $\mathrm{Hb})$

(i) $\mathrm{AG}^{*}=104.8+29.7 \times \mathrm{HbA} 1 \mathrm{c}-18.4 \times \mathrm{Alb}-4.7 \times \mathrm{Hb}$ [6]

*Average glucose.

\section{Results}

Out of 979 patients receiving $\mathrm{HD}$ at the time, $42 \%$ had Diabetes Mellitus (DM). Total number of diabetic patients receiving $\mathrm{HD}, n=412$ ( $42 \%$ of all $\mathrm{HD}$ patients). There was a significantly higher number of South Asians and older people with diabetes compared to the nondiabetic HD cohort $(p<$ 0.0001) (Table 1).

$39 \%$ of patients Trust wide had poorly controlled diabetes defined as HbAlc $<5.4 \%(36 \mathrm{mmol} / \mathrm{mol})$ or $>8 \%$ $(64 \mathrm{mmol} / \mathrm{mol}) .7 \%$ of these were at high risk defined as HbAlc $>10 \%(86 \mathrm{mmol} / \mathrm{mol})$.

Significant differences were seen with various biochemical and clinical parameters (ALP, Hb, sodium, and pre-HD systolic BP) when comparing each HbAlc category (Table 2). However, when each at-risk category (HbAlc outside the target range of $5.4 \%-7.9 \%$ ) was compared to the optimally controlled group (HbA1c 5.4\%-7.9\%) using Dunn's multiple comparison testing, there were no significant differences seen between the groups.

There was an increase of $16 \%$ of patients with poorly controlled diabetes with $\mathrm{HbAlc}$ adjusted for $\mathrm{Alb}$ and $\mathrm{Hb}$ (Figure 1).

3.1. Correlations. Higher HbAlc is associated with larger fluid gains as there is a small $(r=0.14)$ but statistically and clinically significant $(p<0.02)$ positive correlation between IDWG and poorly controlled diabetes (Figure 2). There is a significant increase in systolic blood pressure with higher HbAlc values. There is a weak significant $(p<$ $0.0001)$ negative correlation $(r=-1.9)$ between poor glycaemic control and predialysis sodium (Figure 3 ). There is a weak $(r=0.12)$ but statistically significant $(p<0.02)$
TABle 1: Demographics.

\begin{tabular}{lcc}
\hline & $\begin{array}{c}\text { Diabetes present } \\
(n=412)\end{array}$ & $\begin{array}{c}\text { No diabetes } \\
\text { present }(n=567)\end{array}$ \\
\hline Ethnicity $n(\%)$ & $90(22)$ & $203(36)$ \\
White & $114(28)$ & $176(31)$ \\
Black & $179(43)$ & $125(22)$ \\
South Asian & $29(7)$ & $63(11)$ \\
Other & $65(57-73)$ & $56(45-70)$ \\
\hline Age (years) & $2.6(1.3-4.9)$ & $2.9(1.1-5.5)$ \\
Dialysis vintage (years) & $228(55)$ & $334(59)$ \\
Male gender $n(\%)$ & &
\end{tabular}

Type of diabetes

$\begin{array}{lc}\text { Type } 1 n(\%) & 15(4) \\ \text { Type } 2 n(\%) & 397(96) \\ \text { Insulin treated } n(\%) & 260(63) \\ \text { Kt/V } & 1.5(1.4-1.7)\end{array}$
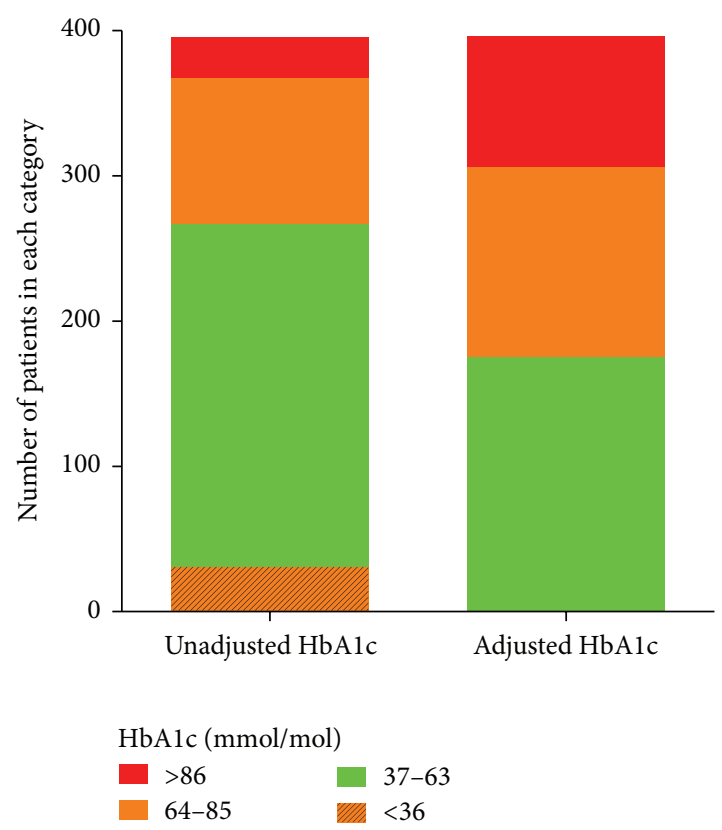

Figure 1: Glycaemic control assessment using HbAlc adjusted for albumin and haemoglobin.

correlation between poor glycaemic control and an increase in bicarbonate (Figure 4). There is a trend between poor glycaemic control, raised CRP, and reduced Alb which is not significant ( $p=0.07$ and $p=0.08$, resp.). The proportion of patients with amputation who have diabetes is greater than those who do not, with 24 versus 2 patients, respectively, with $46 \%$ (11 patients) having an $\mathrm{HbAlc}>8 \%$ (65 mmol $/ \mathrm{mol})$. No other correlations between poor glycaemic control and other biochemical markers were observed (haemoglobin, ferritin, TSAT, WCC, potassium, phosphate, $\mathrm{PTH}$, and vitamin D). 
TABLE 2: Comparison of biochemistry of diabetic cohort according to glycaemic control.

\begin{tabular}{|c|c|c|c|c|c|}
\hline \multirow{2}{*}{ Variable } & $<5.4 \%$ & $5.4-7.9 \%$ & $8-9.9 \%$ & $>10 \%$ & \multirow{2}{*}{$p$ value } \\
\hline & $<36 \mathrm{mmol} / \mathrm{mol}$ & $37-63 \mathrm{mmol} / \mathrm{mol}$ & $64-85 \mathrm{mmol} / \mathrm{mol}$ & $>86 \mathrm{mmol} / \mathrm{mol}$ & \\
\hline Urea $(\mathrm{mmol} / \mathrm{L})$ & $18.5(10.8-21.5)$ & $16.8(13.2-22.9)$ & $17.5(12.8-21.3)$ & $17.5(9.4-23.8)$ & 0.98 \\
\hline Creatinine $(\mu \mathrm{mol} / \mathrm{L})$ & $682(570-839)$ & $706(571-845)$ & $710(558-853)$ & $728(624-854)$ & 0.77 \\
\hline Albumin $(\mathrm{g} / \mathrm{L})$ & $40(37-43)$ & $40(38-42)$ & $41(38-43)$ & 40 (37-41) & 0.09 \\
\hline CRP (mg/L) & $6(5-15)$ & $6(5-20)$ & $6(5-14)$ & $6(5-17)$ & 0.87 \\
\hline $\mathrm{Hb}(\mathrm{g} / \mathrm{dL})$ & $10.3(8.9-11.2)$ & $10.6(9.6-11.5)$ & $10.9(10-11.7)$ & $11(9.8-11.9)$ & 0.02 \\
\hline Ferritin (mcg/L) & $394(195-571)$ & $445(279-623)$ & 458 (291-647) & $496(277-837)$ & 0.69 \\
\hline TSAT (\%) & $22(17-29)$ & $25(21-32)$ & $26(21-34)$ & $26(21-35)$ & 0.2 \\
\hline Calcium (mmol/L) & $2.3(2.2-2.4)$ & $2.3(2.2-2.4)$ & $2.3(2.2-2.4)$ & $2.2(2.1-2.3)$ & 0.06 \\
\hline Phosphate (mmol/L) & $1.5(1.3-1.9)$ & $1.4(1.1-1.7)$ & $1.5(1.2-1.9)$ & $1.5(1.3-1.9)$ & 0.2 \\
\hline PTH (pmol/L) & $44(36-91)$ & $40(20-52)$ & $34(16-57)$ & $41(32-65)$ & 0.1 \\
\hline ALP (unit/L) & $99(64-138)$ & $117(85-162)$ & $104(80-145)$ & $134(91-224)$ & 0.01 \\
\hline Sodium (mmol/L) & $139(138-141)$ & $138(136-140)$ & $139(137-141)$ & $138(135-140)$ & 0.002 \\
\hline Bicarbonate (mmol/L) & $22(20-23)$ & $22(20-24)$ & $22(20-24)$ & $22(22-24)$ & 0.4 \\
\hline Potassium (mmol/L) & $5.1(4.6-5.7)$ & $4.8(4.5-5.5)$ & $4.9(4.4-5.4)$ & $4.8(4.5-5.5)$ & 0.5 \\
\hline $\mathrm{Kt} / \mathrm{V}$ & $1.4(1.4-1.8)$ & $1.5(1.3-1.7)$ & $1.6(1.4-1.7)$ & $1.4(1.4-1.6)$ & 0.61 \\
\hline Pre-HD systolic BP (mm/Hg) & $141(131-159)$ & $158(138-175)$ & $150(132-170)$ & $179(133-202)$ & 0.02 \\
\hline
\end{tabular}

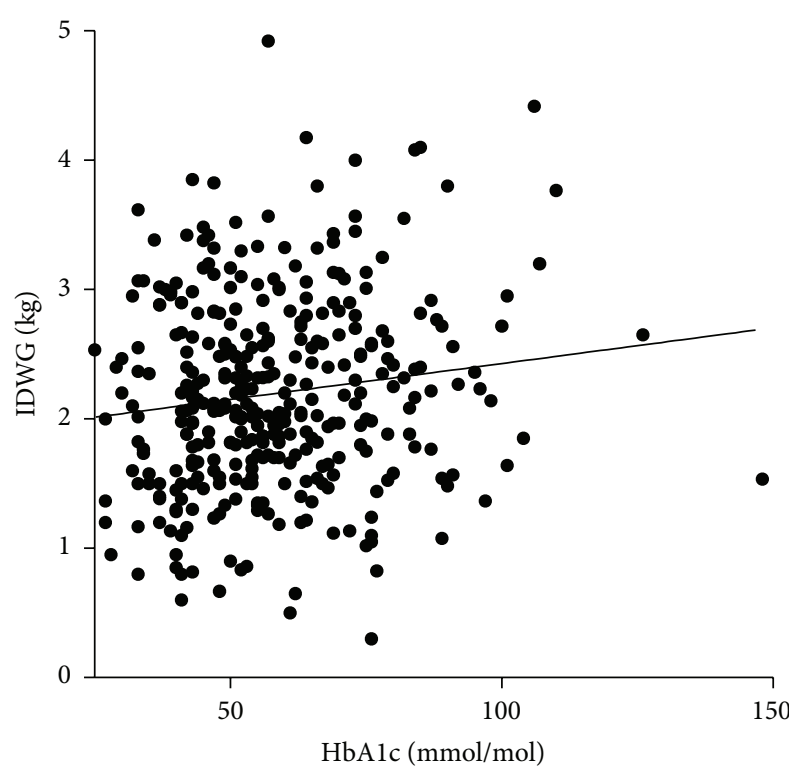

Figure 2: Correlation between glycaemic control and interdialytic weight gains.

\section{Discussion}

There is scant information published nationally or internationally on glycaemic control in HD-dependent diabetic patients. The renal registry has no data on glycaemic control of RRT patients.

4.1. Assessment of Glycaemic Control. There are several challenges in accurately assessing glycaemic control in this patient group. In the diabetic population without diabetic nephropathy and before RRT, HbAlc test is the gold standard test used to assess long-term glycaemic control. An HbAlc

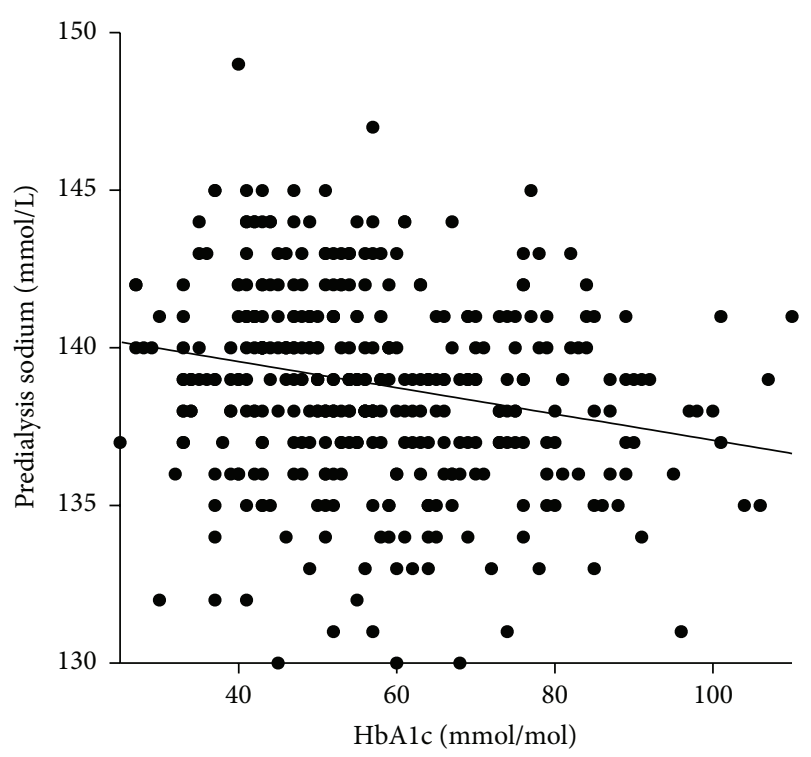

FIGURE 3: Correlation between glycaemic control and predialysis sodium.

test will reflect the average amount of glucose a red blood cell (RBC) was exposed to during its life span.

There are several issues affecting the accuracy of HbAlc tests with ESRF. Urea derived isocyanate results in carbamylated $\mathrm{Hb}$ which is indistinguishable from glycated $\mathrm{Hb}$, giving a false elevation in readings. Other inaccuracies arise from disruptions to RBC life span on which the test is based. Iron deficiency, $B_{12}$, or folate deficiencies also give falsely high readings as they extend $\mathrm{RBC}$ life span. Reduced RBC life span as a consequence of dialysis, recent transfusions and accelerated erythropoiesis result in falsely low results due to shorter periods of exposure to glucose. 


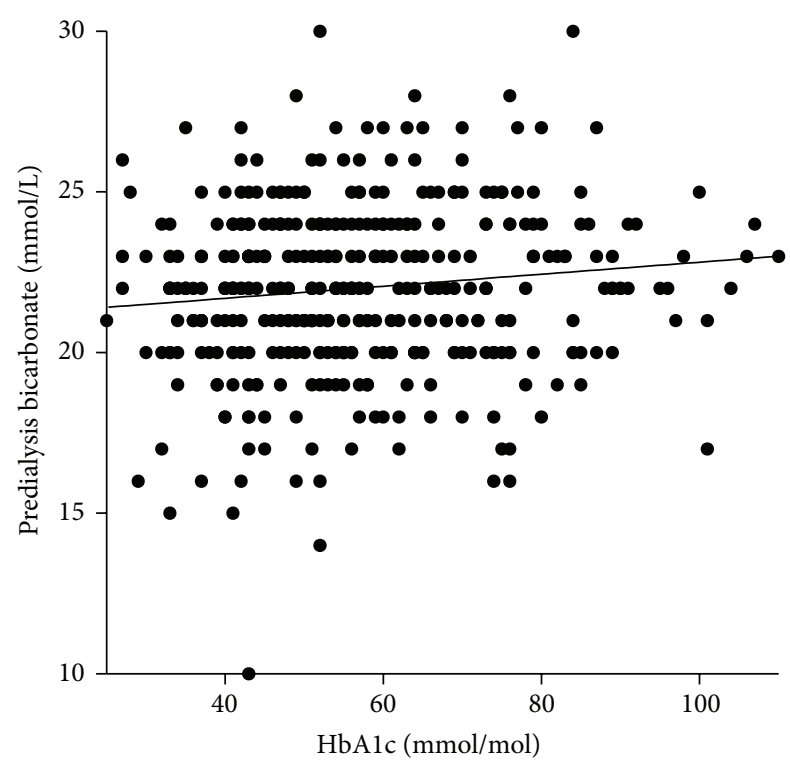

FIGURE 4: Correlation between glycaemic control and predialysis bicarbonate.

Other tests are available such as glycated albumin or glycated fructosamine. These reflect control over a shorter time period and are less affected by the unstable haemodynamic environment as HbAlc. Other factors such as increased protein turnover and malnutrition can affect the accuracy and validity of these tests. Their advantages and disadvantages have been discussed in several papers [7-9]. There are scant long-term trials looking at glycated albumin and chronic complications of diabetes, although one small long-term study found that glycated albumin correlated well with cardiovascular mortality [10]. A consensus on the best methods for assessing long-term glycaemic control in this patient cohort has yet to be reached. Clearly, there is a need for longer, more extensive research in this area. While there are good arguments for using these tests over $\mathrm{HbAlc}$, at present, HbAlc remains the test used most often to monitor and determine glucose control in HD patients.

4.2. Adjusted HbAlc. A recent large study $(n=11,986)$ [6], having recognized anaemia, malnutrition, and inflammation's impact on survival in this patient cohort, has developed equation models adjusting for these confounding factors including $\mathrm{Alb}$ (model 3, $\left.R^{2}=0.483\right)$, Alb $+\mathrm{Hb}$ (model 4, $\left.R^{2}=0.486\right)$, and $\mathrm{Alb}+\mathrm{Hb}+$ age $+\operatorname{race}\left(\operatorname{model} 5, R^{2}=0.491\right)$. These all showed a stronger association than the DCCT $\mathrm{A}_{1 \mathrm{c}}$ derived average glucose equation $\operatorname{did}\left(R^{2}=0.468\right)$ with daily blood glucose. As this study was based in the USA, where ethnicity is very different to the present cohort, we applied model 4 to the data.

Following this adjustment, the number of patients with poor glycaemic control rose from $39 \%$ to $55 \%$, eliminating those who appeared to have very low HbAlc. This highlights the concern of using tests which are inaccurate in this patient cohort. Using standard HbAlc results misclassifies patients into lower risk categories; care therefore is not being efficiently or effectively targeted.

The most accurate method of assessing glucose control is regular self-monitoring of plasma glucose with finger prick tests. Target glucose levels for diabetic patients on HD suggested by one study were fasting $<7.8 \mathrm{mmol} / \mathrm{L}$ and postprandial $<11.1 \mathrm{mmol} / \mathrm{L}$ [11], giving an average $\mathrm{HbAlc}$ reading of $<9 \%$. Compliance and adherence are issues with this method as they involve regular pre- and postprandial daily tests which some patients find difficult to manage.

4.3. HbA1c Targets. While target HbAlc levels for diabetic population without CKD or ESRF are clearly defined based on large-scale studies (DCCT/EDIC, ACCORD, ADVANCE, and VADT), a consensus on HbAlc levels for the diabetic population receiving RRT has not been established. Current advice is centered around the prevention of hyperglycaemia and microvascular complications of diabetes.

(i) Dialysis Outcomes and Practice Patterns Study (DOPPS). It is $7 \%-8 \%$ (53-64 mmol $/ \mathrm{mol})$, suggesting lower end for younger patients with fewer comorbidities and higher end for older patients with greater number of comorbidities [12].

(ii) Kidney Disease Outcomes Quality Initiative (KDOQI). CKD population is $7 \%(53 \mathrm{mmol} / \mathrm{mol})$, although in their rationale they mention that HbAlc levels of 7$9 \%$ are associated with better outcomes for survival, hospitalization, and CVD in patients on haemodialysis in most but not all observational studies [13].

(iii) Renal association. It is $<7.5 \%(<58 \mathrm{mmol} / \mathrm{mol})$ [14].

Using survival and cardiovascular mortality as outcomes, several studies have attempted to stratify optimal and suboptimal glucose control. The most recent meta-analysis of observational studies suggested a J shaped curve relationship where an increase in mortality was associated with HbAlc $<5.4 \%$ and $>8.5 \%[15]$.

Ricks et al. [16], looking at $>54,000$ patient, also found increased mortality risks with $\mathrm{HbAlc}$ below and above $7 \%-$ $7.9 \%$, with $<5 \%$ yielding hazard ratio of $1.35,>8 \%$ HR of 1.06 and $>10 \%$ HR of 1.19 .

There are no published national data looking at glycaemic control for diabetic patients on $\mathrm{HD}$; therefore, it is difficult to assess whether the glycaemic control of the present cohort is better or worse than others. Irrespective, poor control in over half of the patients indicates that more directed and effective care is needed.

As noted by O'Toole et al. [17], besides the inherent problems with using HbAlc as a measure of glycaemic control in this population, there are several further confounding factors that must be considered when using HbAlc levels as a target outcome. Patients with very poor glycaemic control at the outset of dialysis are likely to have worse outcomes. In addition, poor glycaemic control is a surrogate for other factors contributing to poor self-care such as smoking and reduced adherence with medication, fluid restriction, and dietary recommendations. 
4.4. Correlations and Additional Complications. Fluid management is one of the main challenges in HD with increased complexity in diabetic patients. Hyperglycaemia triggers osmoreceptors to stimulate thirst, leading to fluid consumption. Large IDWG and fluid overload lead to volume expansion and cardiac hypertrophy $[18,19]$ exacerbating pulmonary and cardiovascular symptoms. There are several methods for assessing IDWG, either in kilograms calculated from postdialysis weight to the following predialysis weight or by percentage weight change from dry weight. There are positives and negatives for each method; the first while being easier to calculate does not include dry weight in its estimation, while the second, allowing for proportional fluid to body mass estimations, relies on an estimated dry weight which may also be inaccurate.

In our study, we defined undesirable IDWG according to the KDOQI rationale of $>2.5 \mathrm{~kg}$ between dialysis sessions [20] and observed a clinically and statistically significant $(p<0.02)$ if weak $(r=0.14)$ correlation between glycaemic control and IDWG (Figure 2). A recent prospective, 3year follow-up study looking at $>10,000$ patients, found an increase in all cause and cardiovascular mortality rate in patients who had $>2 \mathrm{~kg}$ IDWG from target weight in $>30 \%$ of dialysis sessions [21]. The effect of glycaemia on IDWG was also reported by Davenport [22] who noted absolute and percentage IDWG was the lowest in the group with the best diabetic control classified as $<6 \%$ versus poor control at $>8 \%$ $(2.0 \pm 1 \mathrm{~kg}$ and $2.76 \pm 1.5 \%$ versus $2.5 \pm 1.1 \mathrm{~kg}$ and $3.3 \pm 1.3 \%$ $(p<0.05)$, resp.). Our study supports the association of poor glycaemic control with excessive fluid intake; therefore, in a diabetic cohort where cardiovascular disease is already more prevalent, it is pertinent to prevent further exacerbation by undesirable IDWG by attempting to control hyperglycaemia.

Recent studies have elucidated an association between low predialysis $\mathrm{Na}$ and all cause and cardiovascular mortality $[23,24]$. A further recent paper that looked at the relationship between predialysis $\mathrm{Na}$ levels, IDWG, and nutritional status found that low $\mathrm{Na}(<136.2 \mathrm{mlEq} / \mathrm{L})$ was associated with increased IDWG and decreased lean body mass [25]. Our study shows that hyperglycaemia may exacerbate low $\mathrm{Na}$ as revealed, a statistically significant association between elevated HbAlc and low $\mathrm{Na}(p<0.0001)$ (Figure 3$)$. Predialysis sodium decreases with worsening glycaemic control due to translocational hyponatraemia. In marked hyperglycemia, extracellular fluid (ECF) osmolality rises and exceeds that of intracellular fluid (ICF). Glucose penetrates cell membranes slowly in the absence of insulin, resulting in movement of water out of cells into the ECF. Serum $\mathrm{Na}^{+}$concentration falls in proportion to the dilution of the ECF and therefore poor glycaemic control may be an additional contributing factor to hyponatraemia, increased mortality risk, high IDWG, and malnutrition.

The statistically significant correlation with elevated bicarbonate levels and raised HbAlc $(p<0.002)$ (Figure 4) was more difficult to explain, as hyperglycaemia usually increases acidosis due to hyperosmolality and release of free fatty acids and ketones, resulting in reduced $\mathrm{pH}$; as such one would expect a lower bicarbonate level with poor glycaemic control. One explanation may be that patients with well controlled glycaemia are better nourished, choosing protein rich foods over carbohydrates. The increased protein intake may result in increased systemic acidity, therefore giving an inverse bicarbonate relationship. A recent paper looking at $\mathrm{pH}$ and bicarbonate association with mortality in $\mathrm{HD}$ patients noted that predialysis elevated $\mathrm{pH}$ was associated with increased risk of mortality but not before or after bicarbonate [26] which may render the association observed clinically insignificant.

Many observational studies have noted that HD patients are chronically inflamed. Insulin resistance and diabetes are also known to increase inflammatory cytokines although the precise mechanism remains unclear. In addition, there may be a reciprocal relationship present where inflammation and infection precipitate hyperglycaemia which in turn exacerbates and prolongs the inflammatory response. Hyperglycaemia is a known driving force for ischemia and poor wound healing which may also explain the far greater number of patients with amputations in the diabetic versus nondiabetic population, with $46 \%$ of patients with amputations having an $\mathrm{HbAlc}>8 \%(65 \mathrm{mmol} / \mathrm{mol})$. A recent metaanalysis corroborated the increased risk of foot ischemia and lower limb amputation with higher HbAlc values [27].

While not a hard outcome like mortality, amputations have a major impact on a patient's QoL. A small interventional study $(n=83)$ by McMurray et al. [28] found that intensive glycaemic control intervention resulted in decreased need for amputations and hospitalisation and increase in QoL.

There may be a relationship between hyponatraemia, inflammation, and nutritional status in HD patients, which the study by Poulikakos et al. [25] tried to explore, although, as with our own study, the associations with CRP and albumin, while showing a positive trend, were not statistically significant.

The strengths of this paper lie in the attempt to stratify diabetic patients on HD into risk categories and observe impact on renal specific clinical parameters such as electrolyte imbalances and IDWG, which has not been done previously in the UK. Study design is a limitation as crosssectional observational studies cannot prove causative effects and the reliance on a single measure of HbAlc to quantify glycaemic control may not be an accurate representation of a patient's long-term glycaemic control.

Nevertheless, while most studies focus on hard outcomes such as mortality, there are many other factors in the patient's journey which are important. Achieving euglycaemia in patients with diabetes in the context of ESRD and HD is complex and multifactorial; however, it is essential for improving their clinical progress and QoL.

\section{Conclusion}

Glycaemic control in many HD dependent patients with diabetes is poor and may lead to additional complications such as high IDWG, electrolyte imbalance, and amputations. Current tests for long-term glycaemic control are inaccurate and may result in misclassification of patients into lower risk categories leading to misdirected management. There 
is an urgent need for further research to provide more accurate tests for long-term monitoring of glycaemic control and long-term prospective studies into interventions for alternative outcomes such as improvement with amputations, inflammation, undesirable IDWG, nutritional status, and QoL.

\section{Conflict of Interests}

The authors declare that there is no conflict of interests.

\section{Acknowledgments}

This work forms part of the research themes contributing to the research portfolio of the Barts Health "Diabetic Kidney Disease Centre," supported and funded by the Barts and the London Charity.

\section{References}

[1] NHS, Diabetes with Kidney Disease: Key Facts, 2011, http://www .yhpho.org.uk/resource/view.aspx?RID=105786.

[2] Diabetes UK, "Diabetes facts and stats," 2014, http://www.diabetes.org.uk/Documents/About\%20Us/Statistics/Diabetes-keystats-guidelines-April2014.pdf.

[3] D. Ansell, J. Feehally, D. Fogarty et al., "UK renal registry 2009: the twelfth annual report of the renal association," Nephron Clinical Practice, vol. 115, supplement 1, 2010.

[4] F. Caskey, A. Davenport, A. Dawnay et al., "UK renal registry 2013 16th annual report of the renal association," Nephron Clinical Practice, vol. 125, no. 1-4, 2013.

[5] W. Schrag, "Diabetes: the dialysis outcomes practice patterns study (DOPPS) results and innovative patient care programs," The Journal Of Nephrology Social Work, vol. 26, 2007.

[6] J. Hoshino, M. Z. Molnar, K. Yamagata et al., "Developing an HbAlc-based equation to estimate blood glucose in maintenance hemodialysis patients," Diabetes Care, vol. 36, no. 4, pp. 922-927, 2013.

[7] M. Speeckaert, W. Van Biesen, J. Delanghe et al., "Are there better alternatives than haemoglobin Alc to estimate glycaemic control in the chronic kidney disease population?" Nephrology Dialysis Transplantation, vol. 29, no. 12, pp. 2167-2177, 2014.

[8] C.-M. Zheng, W.-Y. Ma, C.-C. Wu, and K.-C. Lu, "Glycated albumin in diabetic patients with chronic kidney disease," Clinica Chimica Acta, vol. 413, no. 19-20, pp. 1555-1561, 2012.

[9] F. E. Vos, J. B. Schollum, and R. J. Walker, "Glycated albumin is the preferred marker for assessing glycaemic control in advanced chronic kidney disease," NDT Plus, vol. 4, no. 6, pp. 368-375, 2011.

[10] K. Fukuoka, K. Nakao, H. Morimoto et al., "Glycated albumin levels predict long-term survival in diabetic patients undergoing haemodialysis," Nephrology, vol. 13, no. 4, pp. 278-283, 2008.

[11] R. H. K. Mak, "Impact of end-stage renal disease and dialysis on glycemic control," Seminars in Dialysis, vol. 13, no. 1, pp. 4-8, 2000.

[12] S. P. B. Ramirez, K. P. McCullough, J. R. Thumma et al., "Hemoglobin $\mathrm{A}_{1 \mathrm{c}}$ levels and mortality in the diabetic hemodialysis population: findings from the Dialysis Outcomes and Practice Patterns Study (DOPPS)," Diabetes Care, vol. 35, no. 12, pp. 2527-2532, 2012.
[13] National Kidney Foundation, KDOQI Clinical Practice Guideline for Diabetes and CKD: 2012 Update, 2012, https://www.kidney.org/sites/default/files/docs/diabetes-ckd-update-2012.pdf.

[14] The Renal Association, "Detection, Monitoring and Care of Patients with CKD," 2011, http://www.renal.org/Clinical/GuidelinesSection/Detection-Monitoring-and-Care-of-Patients-with -CKD.

[15] C. J. Hill, A. P. Maxwell, C. R. Cardwell et al., "Glycated hemoglobin and risk of death in diabetic patients treated with hemodialysis: a meta-analysis," American Journal of Kidney Diseases, vol. 63, no. 1, pp. 84-94, 2014.

[16] J. Ricks, M. Z. Molnar, C. P. Kovesdy et al., "Glycemic control and cardiovascular mortality in hemodialysis patients with diabetes: a 6-year cohort study," Diabetes, vol. 61, no. 3, pp. 708715, 2012.

[17] S. M. O'Toole, S. L. Fan, M. M. Yaqoob, and T. A. Chowdhury, "Managing diabetes in dialysis patients," Postgraduate Medical Journal, vol. 88, no. 1037, Article ID 130354, pp. 160-166, 2011.

[18] C. Zoccali, F. A. Benedetto, G. Tripepi, and F. Mallamaci, "Cardiac consequences of hypertension in hemodialysis patients," Seminars in Dialysis, vol. 17, no. 4, pp. 299-303, 2004.

[19] N. Sharpe, "Left ventricular remodeling: pathophysiology and treatment," Heart Failure Monitor, vol. 4, no. 2, pp. 55-61, 2003.

[20] KDOQI, Clinical Practice Guidelines for Cardiovascular Disease in Dialysis Patients, 2005, http://www2.kidney.org/professionals/KDOQI/guidelines_cvd/.

[21] J. E. Flythe, A. V. Kshirsagar, R. J. Falk, and S. M. Brunelli, "Associations of posthemodialysis weights above and below target weight with all-cause and cardiovascular mortality," Clinical Journal of the American Society of Nephrology, vol. 10, no. 5, pp. 808-816, 2015.

[22] A. Davenport, "Interdialytic weight gain in diabetic haemodialysis patients and diabetic control as assessed by glycated haemoglobin," Nephron: Clinical Practice, vol. 113, no. 1, pp. c33c37, 2009.

[23] S. S. Waikar, G. C. Curhan, and S. M. Brunelli, "Mortality associated with low serum sodium concentration in maintenance hemodialysis," The American Journal of Medicine, vol. 124, no. 1, pp. 77-84, 2011.

[24] M. Hecking, A. Karaboyas, R. Saran et al., "Predialysis serum sodium level, dialysate sodium, and mortality in maintenance hemodialysis patients: the Dialysis Outcomes and Practice Patterns Study (DOPPS)," American Journal of Kidney Diseases, vol. 59, no. 2, pp. 238-248, 2012.

[25] D. Poulikakos, V. Marks, N. Lelos, and D. Banerjee, "Low serum sodium is associated with protein energy wasting and increased interdialytic weight gain in haemodialysis patients," Clinical Kidney Journal, vol. 7, no. 2, pp. 156-160, 2014.

[26] T. Yamamoto, S. Shoji, T. Yamakawa et al., "Predialysis and postdialysis ph and bicarbonate and risk of all-cause and cardiovascular mortality in long-term hemodialysis patients," American Journal of Kidney Diseases, vol. 66, no. 3, pp. 469-478, 2015.

[27] M. Kaminski, A. Raspovic, L. McMahon et al., "Risk factors for foot ulceration and lower extremity amputation in adults with end-stage renal disease on dialysis: a systematic review and meta-analysis," Nephrology Dialysis Transplantation, 2015.

[28] S. D. McMurray, G. Johnson, S. Davis, and K. McDougall, "Diabetes education and care management significantly improve patient outcomes in the dialysis unit," American Journal of Kidney Diseases, vol. 40, no. 3, pp. 566-575, 2002. 


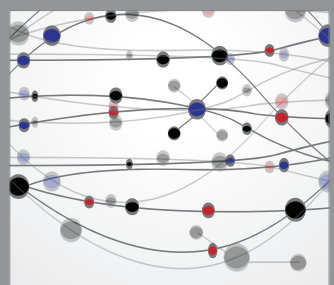

The Scientific World Journal
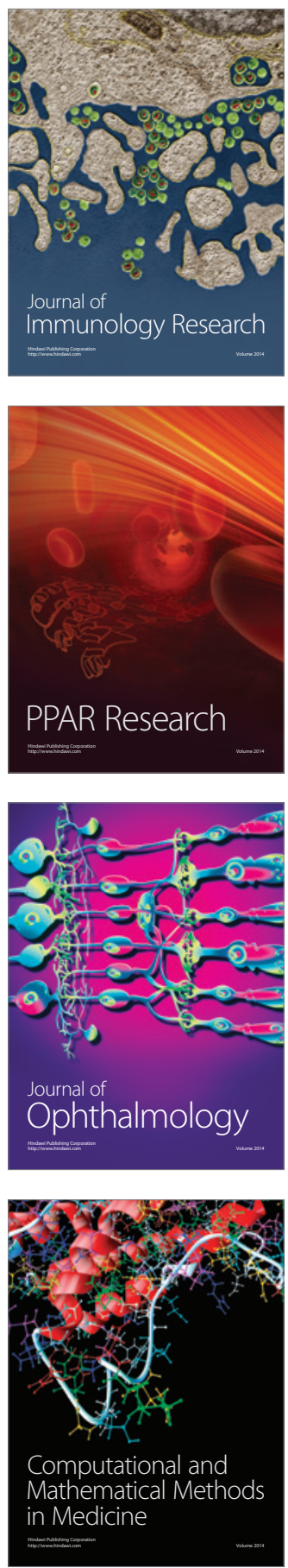

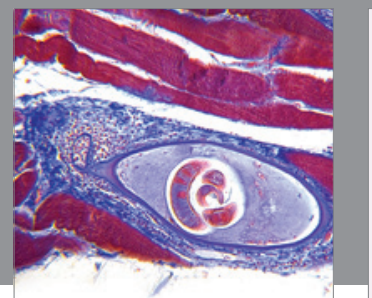

Gastroenterology

Research and Practice
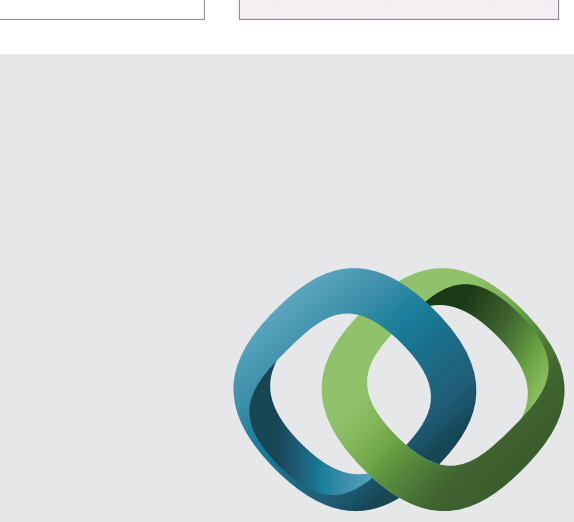

\section{Hindawi}

Submit your manuscripts at

http://www.hindawi.com
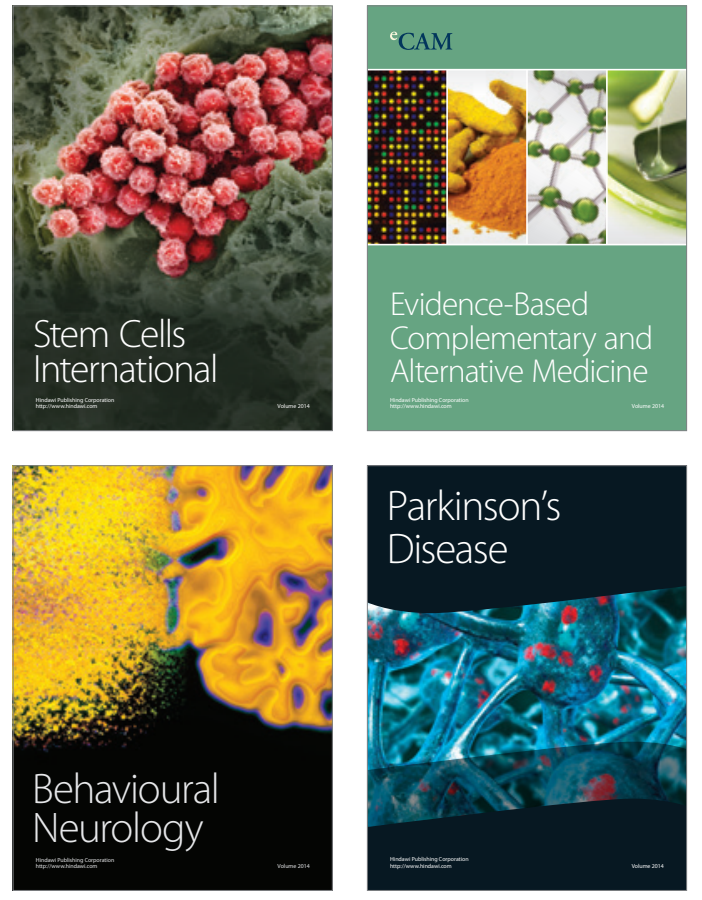
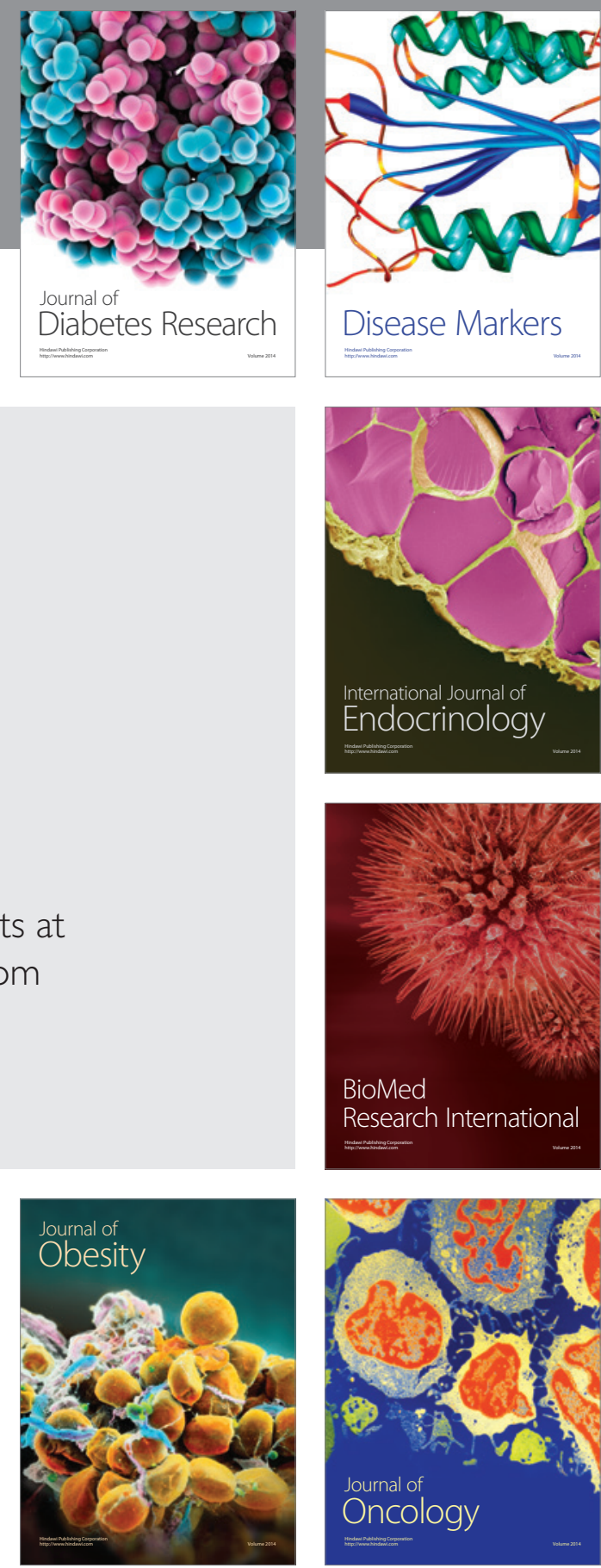

Disease Markers
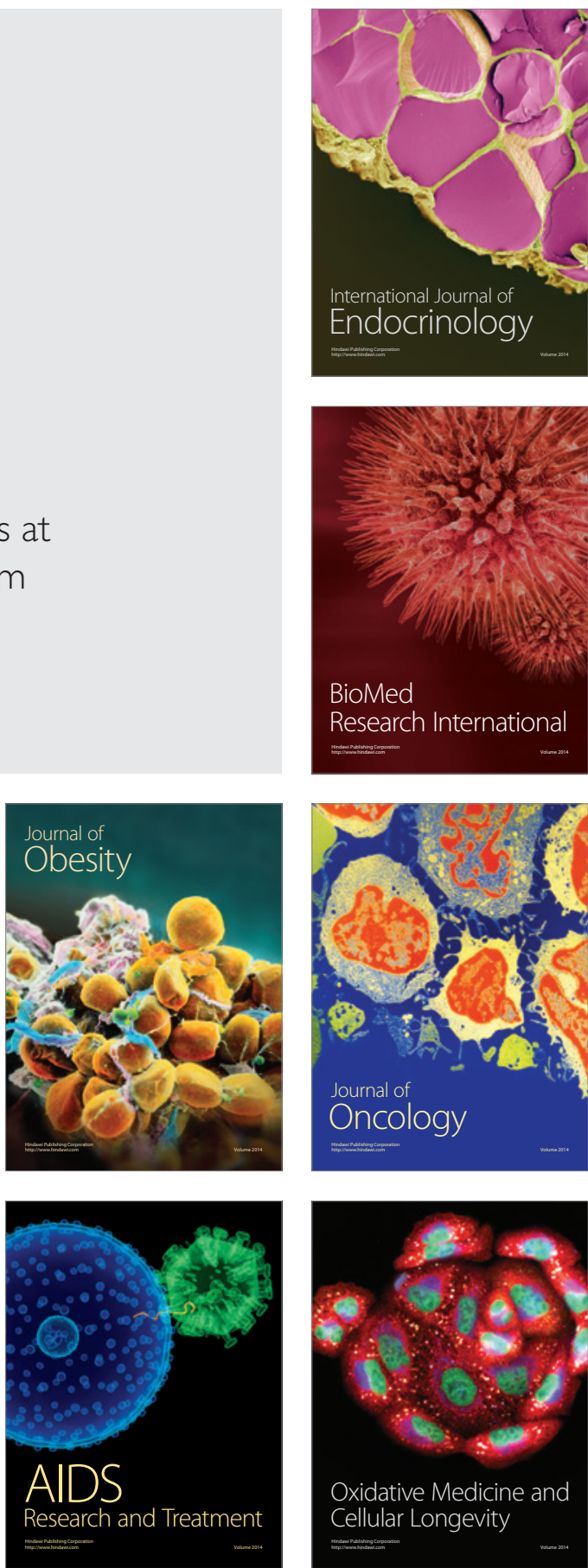